VIadeta Đukic, kapetan I klase

\section{Otkrivanje opasnosti i kontrola kontaminacije pri hemijskim udesima u miru}

\section{Uvod}

Mnogi garnizoni i kasarne okruženi su ili se nalaze u blizini objekata hemijske industrije. Takvi objekti potencijalno mogu ugroziti okolna naselja i vojne objekte u sluěaju da u procesu tehnoloske obrade materijala dođe do nekog akcidenta.

Do sada je dolazilo do industrijskih trovanja sa teskim posledicama, pa je stoga verovatno da će sličnih događaja biti i ubuduce, što nameće potrebu obezbeđenja jedinica od mogucih udesa u miru.

Radi toga, na nivou garnizona obrazovana su odgovarajuća stručna koordinaciona tela, sa zadatkom da preduzmu sve potrebne mere kako bi se sprečile ili umanjile posledice mogućih udesa.

Ova tela su u svom radu naisla na brojne probleme, a jedan od njih, o kojem će u ovom radu biti reči, jeste i otkrivanje opasnosti.

\section{Opšti problemi otkrivanja opasnosti}

$\mathrm{U}$ svim akcidentnim situacijama u svetu došlo je do identične situacije signal za opasnost nije došao na vreme [8].
Nije moguće razmotriti uzroke svih socioloskih, ideoloških i drugih aspekata, ali je cinjenica da su u svim situacijama obaveštenja kasnila upravno proparcionalno težini udesa. Uzroci mogu biti: nepoznavanje opasnosti, kasno otkrivanje opasnosti, strah od posledica, pa sve do onih najdrastičnijih, kao što su strah od odgovornosti i mogućnosti zatvaranja postrojenja (Bopal), mogućnost posledica globalnih razmera (Cernobil), politicki razlozi, nedolazak stranih turista, i dr.

Reakcije na akcident u našoj zemIji obično su se javljale nakon više sati zakašnjenja (na primer: požar u skladištu veštačkog đubriva u Sibeniku 5 sati; uklanjanje posledica pri prevrtanju cisterne sa vinil-hloridom u Pančevu počelo je nakon više od 10 sati, itd.).

Prilikom teških akcidenata u drugim zemljama prolazilo je i vise dana od udesa do upozorenja na opasnost.

Poznato je da većina otrovnih materija ima kumulativna svojstva, tj. vremenom se u organizmu ljudj izloženih intoksikaciji kumulira toksična doza, koja može biti smrtna ili uzrok trajnih poremećaja.

Trovanje može biti akutno ili hronična, a uzrokovano je prodiranjem ot- 
rova u organizam preko organa za disanje, varenje, kroz sluzokožu ili kožu.

Dakle, osnovni problem kojim se bavi ovaj rad jeste kako otkriti opasnost pre nego što dođe do posledica udesa.

\section{Mogućnosti otkrivanja opasnosti}

Otrovi u atmosferi najčešce nisu pristupačni ljudskim čulima, ili su to u neznatnoj meri. Osnovni načini otkrivanja mogu se sistematizovati na način prikazan na slici $1,[10]$.

\section{Vreme otkrivanja opasnosti}

To vreme se izračunava na sledeći način $[2,3]$ :

$$
\mathrm{T}=\frac{\mathrm{D}}{\mathrm{V}_{\mathrm{v}}}-\mathrm{60}[\mathrm{min} .] \quad \ldots
$$

gde je:

D — udaljenost objekta JNA od najbližeg punkta na kojem može dó́i do udesa $[\mathrm{m}]$;

$\mathrm{V}_{\mathrm{v}}$ - brzina vetra kojim otrovni oblak stiže do objekta JNA zadržavajući toksična svojstva $[\mathrm{m} / \mathrm{s}\rceil ;$

$\mathrm{V}_{\mathrm{v}}-$ const. $=5-8[\mathrm{~m} / \mathrm{s}]$.
MOGUĆNOSTI OTKRIVANJA

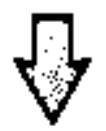

INSTRUMENTALNO

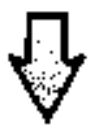

ELEKTRO-HEMJSKOM

METODOM

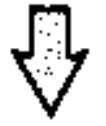

GASNOM-HROMALOGRAFIJOM

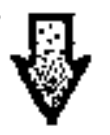

MASENOM-SPEKTROMETRIJOM

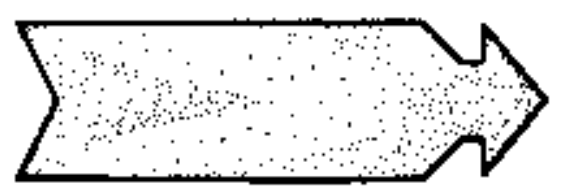

VIZUELNO

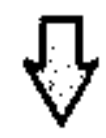

OSMATRANJEM

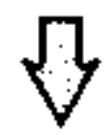

BIOLOŠKIM METOOAMA

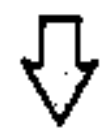

ORGANOLEPTIČKIM

ME TOOAMA

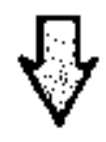

PREPOZNAVANJEM

SMPTOMA TROVANJA

Sl. 1 Mogucinost otkrivanja hemijske kontaminacije

Sve ove metode mogu se ostvariti u raznim fazama kontrole kontaminacije. Međutim, u industriji se koristi veliki broj toksičnih materija, koje mogu za veoma kratko vreme ugroziti ljudstvo na drastičan način i sa katastrofalnim posledicama. Zbog toga, pre svega, treba odgovoriti na pitanje: koliko imamo vremena na raspolaganju da otkrijemo opasnost, da bi ljudstvo bilo sposobno da preduzme mere zaštite pre nego što dođe do posledica?
Primer: kasarna je udaljena $3 \mathrm{~km}$ od objekta koji proizvodi amonijak. $\mathrm{Ka}$ da će biti ugrožena?

$$
\mathrm{T}=\stackrel{3000}{5}_{60}=10 \text { minuta }
$$

Međutim, u ovoj situaciji je nužno da jedinica bude snabdevena specijalnim cedilima koja stite od amonijaka. Ukoliko jedinica nije snabdevena tak- 
vim cedilima, koristimo sledeći obrazac $[4,6]$ :

$$
\left.\mathrm{T}=\underset{\mathrm{V}_{\mathrm{v}}}{\mathrm{D}}: 60\right)-\left(\mathrm{T}_{\mathrm{p}}+\mathrm{T}_{\mathrm{u}}\right) \quad \ldots
$$

gde je:

$\mathrm{T}_{\mathrm{u}}$ - vreme potrebno da se jedinica uzbuni u najnepovoljnijim uslovima, oformi kolonu za evakuaciju i primi naređenje (noću, staresine odsutne). Ovo vreme utvrđuje se probom i snimanjem normi;

$\mathrm{T}_{\mathrm{p}}$ - vreme koje je potrebno da jedinica izađe van opasne zone $u$ predviđeni rejon evakuacije.

Primer: $T_{u}=5$ '; $T_{p}=5$, a $T=0$ uz ranije uzete vrednosti za $\mathrm{D}$ i $\mathrm{V}_{\mathrm{v}}$.

Iz toga se može zaključiti da je ovakva jedinica ugrožena u visokom stepenu i da njen komandant mora posvetiti izuzetnu pažnju zaštiti od uđesa.

Ukoliko je $T>0$, vreme za davanje signala orijentirno možemo proceniti prema obrascu:

$$
\mathrm{T}_{1}=-\frac{1}{2} \mathrm{~T} \quad \ldots
$$

Primer: ukoliko je jedinica udaljena $5 \mathrm{~km}$ od mesta udesa, a vreme reakcije $\left(\mathrm{T}_{\mathrm{p}}+\mathrm{T}_{\mathrm{u}}\right)$ iznosi 15 minuta, koliko imamo vremena da otkrijemo opasnost?

$$
\begin{gathered}
\mathbf{T}_{1}=\frac{1}{2} \cdot\left[\left(\frac{\mathrm{D}}{\mathrm{V}_{\mathrm{v}}}: 60\right)-\left(\mathbf{T}_{\mathrm{p}}+\mathrm{T}_{\mathrm{u}}\right)\right]= \\
=0,83^{\prime} \approx 50^{\prime},
\end{gathered}
$$

Naravno , ukoliko zaštitne maske imaju zaštitnu moć za medij kod kojeg je došlo do udesa, vreme reakcije biće 0 , a tada je vreme uzbunjivanja:

$$
\mathrm{T}_{1}=8^{\prime} 20^{\prime} \text { ' }
$$

U većem broju slučajeva zaštitna maska ima ograničenu zaštitnu moć. Koliko ona iznosi nije naučno potvrđeno, pa na osnovu iskustva inžinjera u RO »Polikem « i RO »Kepol« iz Zadra možemo pretpostaviti da ce zaštitna mœ cedila orijentirno iznositi 5-15'.
U tom slucaju ovo vreme se oduzima od vremena reagovanja i vreme uzbunjivanja izračunava se po obrascu:

$\mathrm{T}_{1}=\frac{1}{2} \cdot\left[\left(\frac{\mathrm{D}}{\mathrm{V}_{\mathrm{v}}}: 60\right)-\left(\mathrm{T}_{\mathrm{p}}+\mathrm{T}_{\mathrm{u}}\right)-\mathrm{T}_{\mathrm{z}}\right]$

što za vrednosti iz gornjeg primera i $\mathrm{T}_{\mathrm{z}}=5$ ' iznosi $\mathrm{T}_{1}=3$ ' 20' '.

Dakle, na osnovu navedenih obrazaca može se orijentirno izračunati potrebno vreme za davanje signala za opasnost (uzbunjivanje jedinica) za svaki konkretan slư̌aj.

U svakom slučaju, možemo zaključiti da je vreme za uzbunjivanje jedinica veoma kratko, pogotovu ako je udes izbio na postrojenjima za obradu visokotoksicnih materija ili materija of kojih cedilo zaštitne maske ne pruža zaštitu (odnosno pruža je ograničeno vreme koje nije egzaktno utvrđeno).

Uopšteno, uzevši, to vreme krece se $u$ rasponu od 1 do 5 minuta.

\section{Mogućnosti jedinica za otkrivanje opasnosti u datom vremenu}

Jedinica ne raspolaže svim sredstvima i mogućnostima navedenim "1 slici 1. Naprotiv, opasnost se može otkriti na sledeći način:

be $0 \mathrm{i0}$;

— dobijanjem informacije od služ-

- uspostavljanjem direktne veze sa dežurnom službom u RO koja posluje sa opasnim materijama;

- osmatranjem;

- upotrebom formacijskih sredstava hemijske detekcije [HD M11B, HD M1, VPHR-54 (S), eventualno AHD, ARHD].

Pošto je prethodno konstatovano da se prva dva nacina, iako najbolja, ne mogu smatrati dovoljno efikasnim, mo. že se zaključiti da je jedino siguran treći način. Upotreba sredstava detekcije moguća je tek kada otrovni gas stigne do kasarne. 
Zbog toga je u kasarnama koje se nalaze u blizini objekata visokog rizika jedini pravi izbor osmatranje tog objekta, što se može organizovati na razne načine, shodno specifičnostima garnizona, uz uslov da bude neprekidno $i$ da određeno ljudstvo bude za to dobro obučeno.

\section{Domet otrovnih isparenja i njihovo trajanje}

Ako jedinica na vreme preduzme potrebne mere, uspešno će biti razrešena početna kriza. Međutim, otrovna isparenja kreću se nošena vetrom izvesno vreme i cesto menjaju pravac kretanja. Od toga zavisi čitav niz zaštitnih mera koje treba preduzeti. Osnova za preduzimanje zaštitnih mera je procena dometa i postojanosti otrovnog oblaka.

Prema postojećem matematickom obrascu [2], domet para može se izražcunati na sledeći način:

$$
X=-\frac{-5 a+\sqrt{25 a^{2}}+\frac{32 \bar{M}}{C \cdot U}}{2}
$$

gde je:

$X$
$a$
$M$
C
U

- domet para;

- dužina KonZ-a pri isticanju kontaminata;

- ukupna masa isteklog kontaminata;

- dozvoljena koncentracija prema standardu;

- orijentirna, prosečna visina kontaminacije $u$ odnosu na tlo.

Do ove jednačine dolazi se primenom jednačine za koncentraciju na nacela za procenu oblika i veličina KonZ-a, datim u Priručniku za procenu i prognozu NH udara, sto je, zatim, ob. rađeno računarom, [7].

Praktično su tri veličine u navedenoj formuli konstantne (za velicinu $U$ obično treba uzeti visinu najviših ljudi, oko $2 \mathrm{~m}$ ili $1,8 \mathrm{~m}$ ).
$\mathrm{Na}$ taj način, celokupni domet zavisi od dužine isticanja tečnosti. $\mathrm{Na}$ primer, ako je iz rezervoara zapremine $5000 \mathrm{t}$ iscurio vinil-klorid u dužini od $200 \mathrm{~m}$, domet isparenja, pri dozvoljenoj koncentraciji od $75 \mathrm{ppm}$ (1 ppm $=2,6$ $\left.\mathrm{mg} / \mathrm{m}^{3}, 75 \mathrm{ppm}=196 \mathrm{mg} / \mathrm{m}^{3}\right)$, iznosiće $97,8 \mathrm{~km}$.

Trajanje opasnog dejstva primarnog i naknadnog oblaka izračunava se po obrascu:

$\mathrm{T}=\left(\frac{\mathrm{L}^{2}+8 \times \mathrm{Ka} \times \mathrm{t}}{\mathrm{u}}\right) \cdot 0,5[\mathrm{~h}]$

gde je:

$\mathrm{T}$ - vreme trajanja otrovnog oblaka;

L - dubina oblaka;

Ko - koeficijent, iznosi 0,65 ;

$t$ - vreme proteklo od nastanka oblaka;

d - brzina vetra.

Iz navedene jednačine proističe da ako je pre 2 časa stvoren otrovni oblak dužine $1700 \mathrm{~m}$, pri vetru brzine $2 \mathrm{~m} / \mathrm{s}$ opasnost od primarnog oblaka trajaće 41,5 sati [2].

Opasnost od naknadnog oblaka izračunava se na isti način, ali počev od krajnje granice postojanosti kapljice na tlu. Postojanost na zemljistu izračunava se po Lajtnerovoj formuli [2]:

$\mathrm{S}=\frac{\mathrm{V}_{\mathrm{d} 1}}{\mathrm{~V}_{\mathrm{d} 2}}=\frac{\mathrm{P}_{1}}{\mathrm{P}_{2}} \cdot \sqrt{\frac{\mathrm{M}_{1} \cdot \mathrm{T}_{2}}{\mathrm{M}_{2} \cdot \mathrm{T}_{1}}[\mathrm{~h}]}$

$V_{\mathrm{tl}}$ - brzina isparavanja vode;

$V_{d^{2}}$ - brzina isparavanja supstance;

$\mathrm{P}_{1}$ - napon para vode;

$\mathrm{P}_{2}$ - napon para supstance;

$\mathrm{M}_{1}$ - molekulska težina vode;

$\mathrm{M}_{2}$ - molekulska težina supstance;

$\mathrm{T}_{1}$ - temperatura ključanja vode;

$\mathrm{T}_{2}$ - temperatura kljuicanja supstance.

Tako se, na primer, može izračunati da pri udesu sa isticanjem kloracetona, postojanost iznosi 1,28 casova. 
Ova jednačina uvažava tzv. normalne uslove (pre svega, temperaturu između $10 \mathrm{i} 30^{\circ} \mathrm{C}$ ); za promenu temperature od $1^{\circ}$, postojanost se na odgovarajući način promeni za oko 10\% (Nernstova teorema).

Isparljivost se može izračunati za razne potrebe (npr. dimenzije KonZ) po sledećem obrascu [2]:

$\mathrm{C}_{2}=\frac{\mathrm{Mx}_{-\mathrm{2} 273 \times \mathrm{Px} 10^{3}}}{22,4 \times \mathrm{Tcx} 760} \underset{\mathrm{T}}{16 \mathrm{MxP}}\left[\mathrm{mg} / \mathrm{m}^{3}\right](8)$

gde je:

M - molekulska težina kontaminata;

$\mathrm{P}$ - napon para kontaminata;

$\mathrm{T}$ - temperatura ključanja kontaminata. gde je:

$\mathrm{V}$ - zapremina oblaka;

$\mathrm{C}_{2}$ - maksimalna koncentracija zasićenja.

Svi navedeni obrasci dati su pod prosečnim uslovima, ne uzimajući $u$ obzir mnoge faktore koji se teško mogı unapred predvideti (pokrivenost tla, meteorološke prilike, karakter tla, uticaj mikroklime, uticaj topografskih objekata, padavine, i sl.), zbog čega u svim procenama treba ići na povećani faktor sigurnosti. Uticaj vetra prikazan je na slici 3.

Navedeni obrasci mogu se na jednostavan način programirati za obradu podataka koriśćenjem informatičkih si-

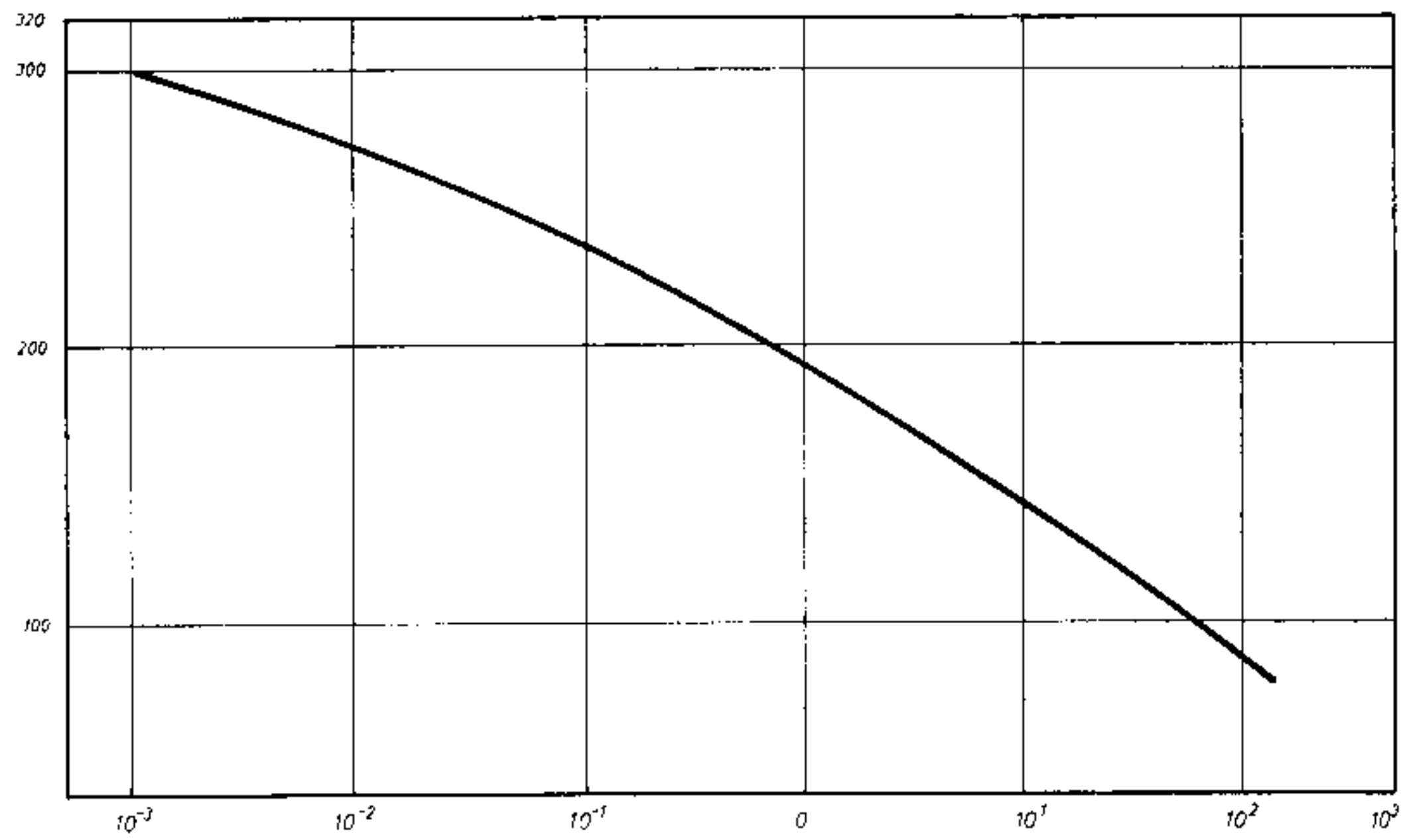

St, 2 Odnos izmedu tacke kljuXanja $(760 \mathrm{~mm} \mathrm{Hg})$ i koncentracije zasićenja

Unošenjem prethodnih parametara za kloraceton lako se može izračunati koncentracija zasićenja, koja iznosi $4,879 \mathrm{mg} / \mathrm{m}^{3}$ (za VCM $2,89 \mathrm{mg} / \mathrm{m}^{3}$, sl. 2).

Zalivaljujući tom obrascu može se izračunati i zapremina oblaka [4]:

$$
\mathrm{V}=\mathrm{M} / \mathrm{C}_{2}\left[\mathrm{~m}^{3}\right]
$$

stema, tako da za određene vrednosti varijabli kompjuter daje korisniku preporuku o postupku koji treba primeniti u raspoloživom vremenu.

Dakle, može se zaključiti da je potrebno stalno praćenje kretanja otrovnog oblaka, koji nošen vetrom može če- 


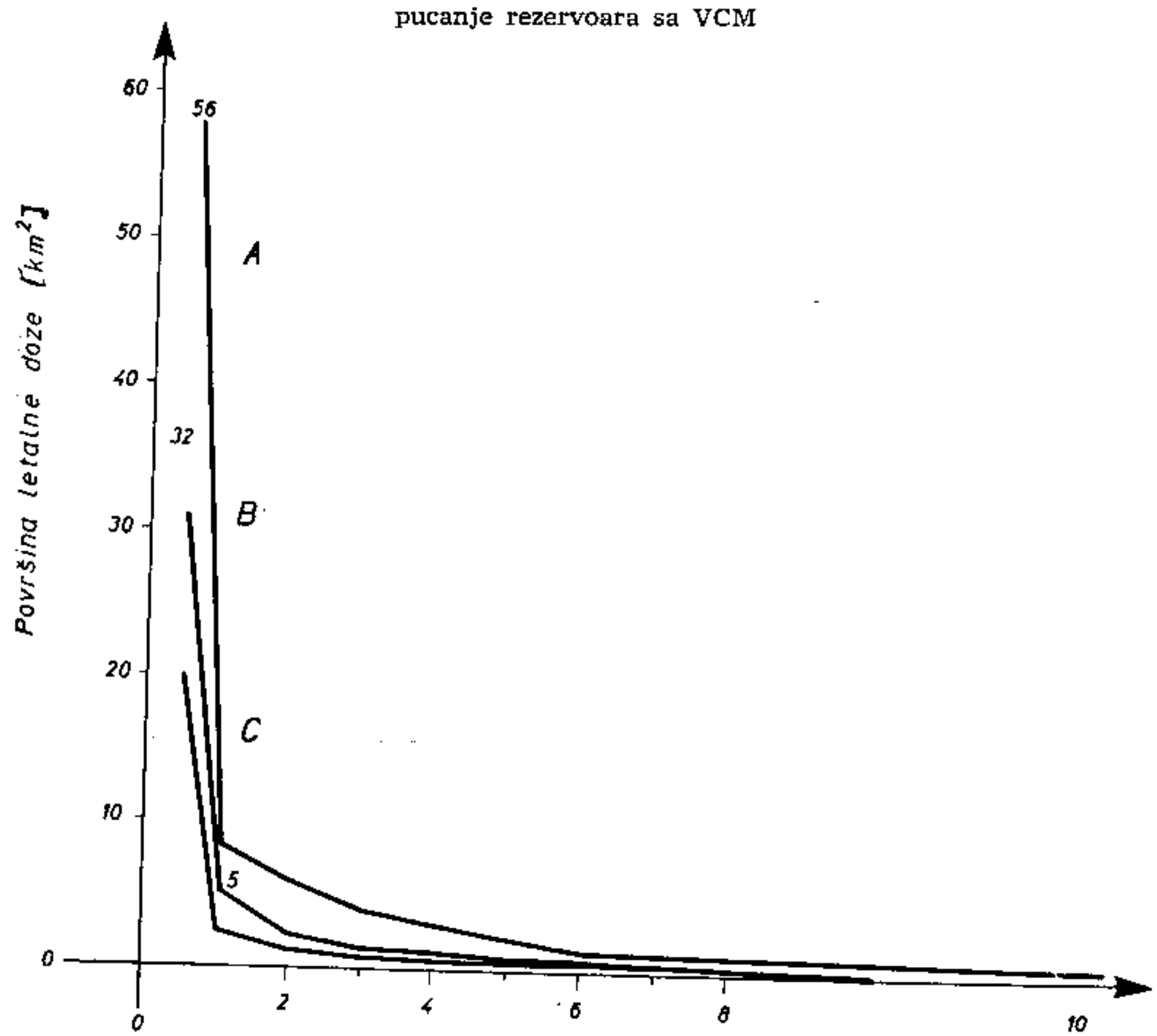

Sl. 3 Površina letalnih doza VCM: A - Pristakanju 100\%; B - Pri istakanju 50\%; C - Pri istakanju $30 \%$

sto menjati pravac i koncentraciju, te potrajati i više dana. Praćenje promene opasnosti predstavlja osnovni uslov svih daljnjih taktičkih i tehničkih postupa$\mathrm{ka}$, te života i rada u uslovima $\mathrm{H}$ - akcidenata u miru.

\section{Rezultati ispitivanja indikatorskih sredstava}

Zbog svega sto smo naveli, kao i zbog velike količine otrovnih materija sa kojima se posluje u mnogim gradovima, izvrక̌cno je opitovanje, sa ciljem da se utvrdi da li se raspoloživa forma- cijska sredstva naših jedinica mogu koristiti za otkrivanje opasnosti.

S obzirom na skromne uslove za izvođenje opita, ispitivanje indikatorskih sredstava zasnovano je na sledecim osnovnim pretpostavkama:

- najpre je izvršena provera indikatorskih sredstava kod veoma visokih koncentracija i eliminisani su gasovi na koje sredstva nisu reagovala;

- zatim je izvršena provera kod ekstremno niskih koncentracija, koje se javljaju u uslovima radnog ambijenta. Sva indikatorska sredstva na kojima se reakcija ispoljila reagovala su istovetno u oba slučaja. 
Vršena ispitivanja su:

— indikatorskim cevčicama iz kompleta HD;

- indikatorskim papiricima;

- specijalnim cevčicama tipa »Dreger $\hat{i}$ »Auer kojima je rok trajanja istekao pre 5 godina;

- indikatorskim cevčicama i papirićima kojima je istekao rok trajanja (cevčice pre: 3,7 i 10 godina);

- Iakmus-papirom;

- proveravana je mogućnost organoleptičke detekcije;

- prikupljeni su podaci o potrebnim merama za pružanje prve pomoći.

Opiti su izvršeni sa svim materijama koje su se $u$ tom periodu nalazile u lučko-industrijskoj zoni grada Zadra, osim sa flourovodoničnom kiselinom koja je bila u specijalnoj ambalaži u tranzitu.

Probe su ponavljane $2-3$ puta, a ako cevčica nije davala rezultate $5-10$ puta.

Materije na kojima su opiti izvršeni su:

- vinil-hlorid (VCM);

- hlor-formijat;

- stiren;

- benzin;

- butil-acetat;

- M. E. glikol;

- heksanon;

- metil-alkohol;

- amonijak.

Pre svega, treba istaći najpovoljnije saznanje u oblasti detekcije, a ono se ogleda u sledećem:

- VMC se ne može otkriti ni na koji drugi nacin osim specijalnim cevčicama. Prag draži mu je visok, tako da se covek koji oseti miris već nalazi pod narkotičnim delovanjem $i$ verovatno se neće prilagođeno ponašati;

- hlor-formijat u atmosferi oslobađa fozgen i može se veoma uspešno otkrivati cevčicom na uputstvom predviđen način;

- sve ostale materije mogu se uspešno otkrivati po mirisu pre nego što za čoveka postanu smrtna opasnost.

Daljni rezultati istraživanja dati su u tabeli.

Može se zaključiti da se skoro sve ove materije mogu otkriti na određeni način, izuzev VCM-a za koji je nužno nabaviti specijalne indikatorske cevěice iz uvoza (kojih ima više tipova, a uvoznik je »Jugomontana«, Beograd). Ima mesta i razmatranju mogućnosti za obuku službenih pasa za otkrivanje opasno-

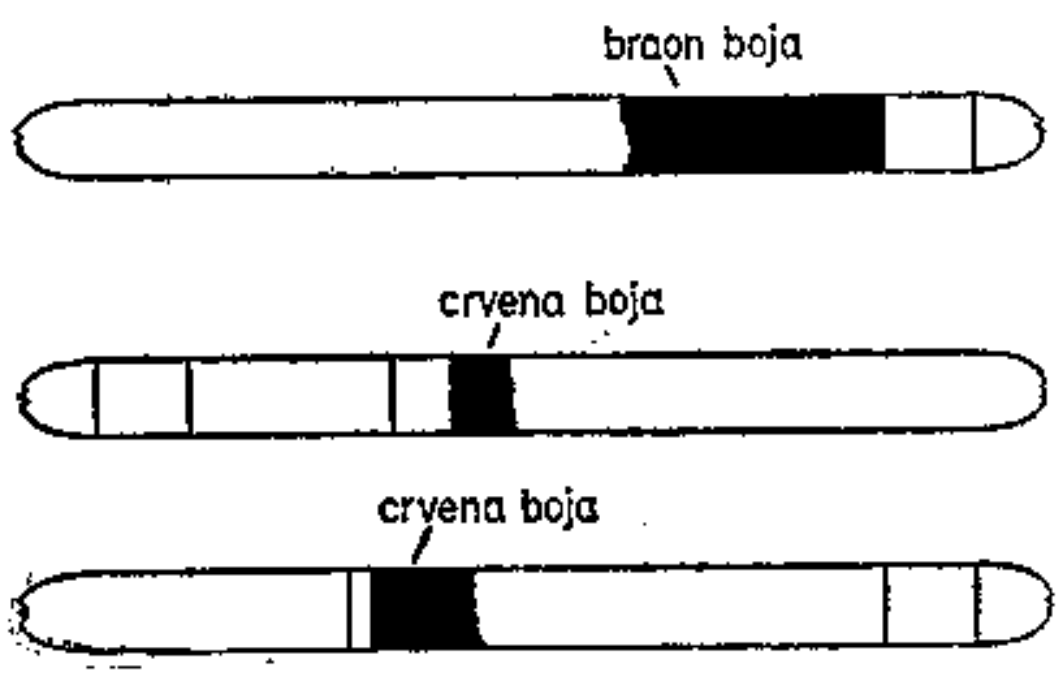

St. 4 Promena boje cevčica

sti, s obzirom na to da se u svetu godisnje otkrije i sintetizuje veliki broj novih materija, no to nije predmet ovog rada.
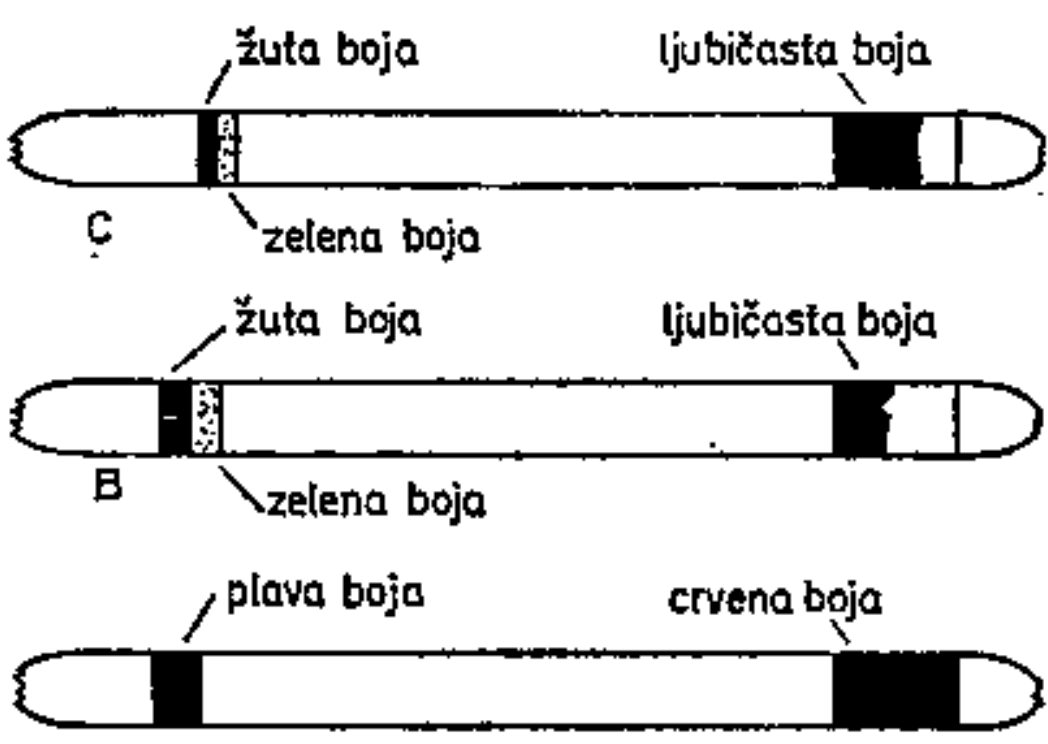

A

St. 5 Promena boje indikatorskih cevcica: A) Butil-acetat; B) Benzin; C) Stiren 
Mogućnost detekcije industrijskih otrounih materija

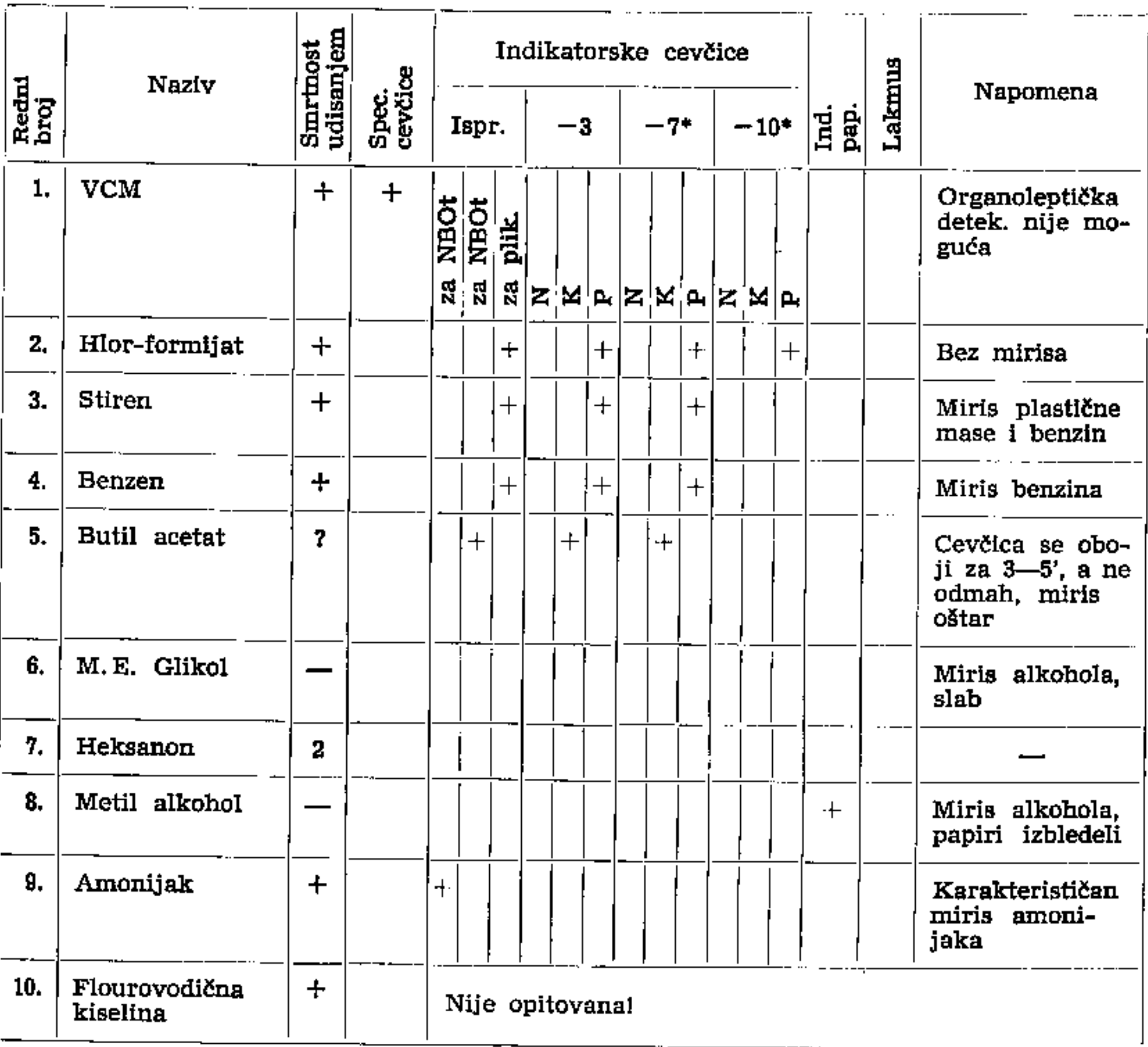

* Istekao rok upotrebe.

Specijalne cevčice za VCM su nešto vece od formacijskih, ali se mogu uspešno koristiti uz pomoć ruxne pumpe hemijskog detektora.

Interesantan je i podatak da se na svim cevčicama (izuzev crvenih pri đotekciji amonijaka) pojavljuje ista boja, koja se vremenom pojačava (za nekoliko minuta), a nestaje posle 12-16 časova, i to (sl.4):

- pri detekciji stirena i benzina javlja se bledoružičasta boja, koja postaje crvena nakon $2-3$ minuta;
- pri detekciji butil-acetata najpre nema promena, da bi posle 5-10 minuta cevčica dobila crvenolịubičastu boju; - pri detekciji amonijaka postupak i boja su isti kao pri detekciji NBOt (sl. 5).

Iz tabele je uocljivo i to da je:

- za detekciju hlor-formijata korišćena žutozelena cevčica po uputstvom predviđenom postupku;

- ista cevčica i postupak korišćeni su pri detekciji stirena $\mathrm{i}$ benzena; 
- za detekciju butil-acetata koriß̌cena plava cevčica, po postupku predviđenom za otkrivanje krvnih BOt.

Indikatorski papirić je izbledeo u prisustvu metil-alkohola, dok na druge materije nije reagovao. Lakmus-papir nije davao nikakvı reakciju.

Iz ranijeg iskustva možemo istaći da je plavom cevčicom uspešno proveravan otrov »ciklon« koji se baca posle obrade skladišta hrane (sastav: 98\% HCN).

Opitovanje sa cevčicama kojima je istekao rok upotrebe ne treba uzeti kao potpuno relevantnu činjenicu. Opitovanje smo izvršili s obzirom na to da ce jedinice garnizona zahvaćenog akcidentom imati veoma veliki utrošak cevčica (prema nekim procenama oko 200 na dan). U takvoj situaciji, cevcice kojima je istekao rok upotrebe mogu se koristiti samo tako što bi patrola prednju granicu otkrivala ispravnim, a kasnije koristila zastarele cevčice, pretežno u rejonima više koncentracije. Za otkrivanje nailazaka para mogu se koristiti isključivo nove cevčice.

\section{Zakljucak}

U ovom radu dati su opšti principi za procenu situacije pri $\mathbf{H}$ udesima $u$

\footnotetext{
Luteratura:
}

[1] Jovic R.: *Kako preživeti hemljsk! rat 1 nafčeśća trovanja u miru氏, NA, 1972, Beograd.

[2] U ABHO-55: *Hemija BOte, viz, Beograd, 1979.

[3] U ABHO-56: nHemljsko oružjeđ, viz, Beograd, I979.

[4] Informacija Ro *POLIKEM*, 1988.

[5] Informacija br. 2 RO POLIKEMc, 1969.

[6] Pejčić M.: sNeki aspekti ponåanja VCM u atmosferis, Rijeka, 1986, privatno izdanje. miru i konkretni rezultati opita proistekli iz potreba jedinica da pravovremeno preduzmu mere zaštite.

$\mathrm{Na}$ žalost, što se moglo i očekivati, pokazalo se da formacijska indikatorska sredstva nisu svemoguća. Međutim, dobijeni rezultati pružaju određenu mogućnost saznanja o tome šta treba ubuduće preduzimati radi obezbeđenja jedinica od udesa u miru.

Organoleptička detekcija još jednom potvrđuje svoj veliki značaj, te sve izvođače obuke upućujemo na što doslednije obučavanje vojnika i starešina u smislu sadržaja tačaka 16-19 Uputstva za PNHBOb taktičkih jedinica KoV.

Dobijeni rezultati mogu da posluže kao osnova za rad stručnih koordinacionih tela (garnizona) za procenu $\mathrm{NH}$ udesa u miru, koji ih mogu veoma jednostavno primeniti i u svom garnizonu, uvodeći parametre koji su relevantni za određenu teritoriju, odnosno industrijsko postrojenje. To je utoliko značajnije što za raznovrsne potencijalno toksične materije nije ekonomski isplativo vršiti posebne opite, već se uz pomoć iznete metodologije mogu pretpostaviti ispravne teoretske osnove, te doneti pravilne odluke. U nekim od takvih situacija to može značiti život za mnogo ljudi.

[7] U ABHO-118:2; *PT1ruð̆nik za prognoze učlnaka NiHU\&, VINC, Beograd, 1987.

[8] Jović J.; oDlverzantskô-teroristička dejstva NHB sredstvimak, VINC, Beograd, $19 B 7$.

[9] Jovié R., C. R.: \$Protivhemijska zastita u mlru i ratux, vojnosanitetski pregled (16/1959, 26/1969, 28/1971, 29/1972).

[10] sInternational devence reviewc, $7 / 67$. 